\title{
Lecturas de lo visible e invisible: una filmación sobre un arte corporal de origen chino en un jardín de París
}

ISABEL CALPE

París

\section{INTRODUCCIÓN}

En este artículo, analizo la experiencia de una filmación de una práctica corporal de origen chino, el Qi Gong ${ }^{1}$, en un pequeño jardín de París, el square René Legall, situado en el barrio de los Gobelins al sudeste de la ciudad.

El grupo de practicantes estudiado, el más numeroso de París, está integrado por unas cien personas, en su mayoría de profesiones liberales y artísticas, que siguen los cursos de Kar Fung Wu Santaro, una maestra china educada en el seno de una familia budista y taoísta que ha recibido su formación en uno de los templos más antiguos de China.

Desde la perspectiva de la antropología visual, el Qi Gong aparece como un sistema visual que se articula en torno a determinados parámetros visibles -el cuerpo en el espacio, el gesto y el movimiento- y en torno a una dimensión más sutil y aparentemente invisible —el $Q i^{2}$, "Souffle", aliento de vida o energía vital.

La filmación suscita interrogantes ¿Qué relación establecemos con las personas que filmamos? ¿Hasta qué límite filmar sin violar la privacidad del otro? ¿Cómo crear una imagen auténtica y fidedigna?

La realización de un film es un modo de conocer al otro. La filmación despierta reacciones, maneras de ver y sentir que permiten valorar en profundidad cómo el Qi Gong es comprendido por el grupo. El roda-

1 Se pronuncia Chi Cong. Generalmente se escribe Qi Gong, pero pueden hallarse otras formas escritas como Chi Kung o Ki Kung.

2 Según la cosmología china, todas las cosas vivientes están constituídas por diferentes $Q i$ o soplos vitales. Los $Q i$ circulan en el organismo humano, en la naturaleza y el universo. El $Q i$ es la respiración que anima todas las cosas vivientes. Corresponde al Prana de los hindúes o al Pneuma de los griegos. En español podríamos denominarlo aliento de vida o hálito. Los franceses lo traducen por "Souffle", término que he preferido conservar. 
je se integra en la investigación etnológica. Imagen y escritura se entrecruzan, complementándose en una visión más amplia sobre el Qi Gong.

Practicado en China desde tiempos remotos, el Qi Gong ha llegado a Occidente a través de los maestros que huyeron de la revolución cultural. Integrado en la práctica médica por Huang $\mathrm{Di}$, el llamado emperador amarillo, en el s. 26 a.C., el Qi Gong es un trabajo corporal destinado a hacer circular el Qi en el organismo. Hoy, la práctica de este arte corporal conoce una gran difusión y se extiende por Europa, América y Asia. En Francia, ha sido recientemente reconocido por el Ministerio de Educación Nacional y podrá ser enseñado en los centros escolares. Según datos de la Federación francesa de Qi Gong y Tai Ji Quan, existen en Ile de France un centenar de lugares de enseñanza.

\section{AL ENCUENTRO DEL OTRO}

Hoy día en el debate epistemológico sobre el cine documental se acepta la idea de que todo film es una construcción de la realidad. "L'idée du vrai est très fragile" dice el conocido documentalista holandés Johan Van der Keuken. Y es que la materia de lo que está hecho eso que denominamos realidad es por naturaleza difícil de aprehender. Al igual que el cineasta de ficción, el documentalista, o el antropólogo cineasta, se ve ante la necesidad de modelar ese material fugitivo que es la "realidad" para darle forma y sentido de acuerdo a su propia visión de las cosas.

Influida por los modos discursivos tradicionales en antropología, una corriente del cine etnológico ha utilizado frecuentemente la imagen como soporte e ilustración del discurso de un narrador, elevado éste a la categoría de verdad objetiva. Por desgracia, a menudo esta voz en off ha substituido la voz del otro, imponiendo una visión restrictiva y etnocéntrica. Recientemente, he visto en la televisión francesa un documental sobre la celebración de un ritual en Indonesia. El discurso del narrador era omnipresente y las pocas secuencias en que había un diálogo entre el oficiante y los participantes del rito ni siquiera habían sido subtituladas. El realizador, me dije, debía de haberse confundido de género y creer estar filmando un documental sobre animales en vez de una película que implicaba a otras personas.

Afortunadamente, el cine documental vive una renovación completa desde hace unos años; ha habido una eclosión de estilos que responden no sólo a nuevas preocupaciones sobre la forma y al lenguaje, sino a un deseo de penetrar en las realidades subjetivas de la experiencia humana. 
Así, el cine documental se ha abierto a dimensiones más personales, más íntimas y más poéticas. Estas dimensiones no son ajenas a la relación que se establece entre el realizador y las personas filmadas. De esta manera, un realizador como Shohei Imamura, que se interesa por el destino de sus compatriotas fuera del Japón, es capaz de establecer una relación muy próxima y personal con los protagonistas de sus documentales. Él mismo aparece en imagen y sus filmes están construidos a partir de la relación espontánea, llena de respeto, interés y confianza, que logra establecer con las personas que filma.

De otro modo, el realizador ruso Alexander Sokurov establece una relación de reserva y discreción, basada más en el silencio que en el diálogo. En uno de sus documentales ${ }^{3}$, Sokurov instala su cámara en la casa de una anciana mujer que vive aislada en la montaña. La cámara recoge el cotidiano de la anciana, los gestos, los momentos de actividad, de recogimiento... La mujer parece ignorar la presencia del realizador, que filma con un extraordinario pudor. Casi al final del film, la mujer rompe el silencio y lee unos versos escritos a la memoria de su marido. En este momento de gran intensidad dramática, el vínculo creado entre esas dos personas a lo largo de los días de comunicación silenciosa se hace visible; la anciana ofrece al realizador lo más precioso de su memoria en un auténtico gesto de don.

La vocación del cine documental y antropológico no sólo es comprender formas de vida, de pensar o de sentir. Toda película es la historia de un encuentro, de ese diálogo visible e invisible que el realizador crea con las realidades y personas con las que entra en relación. Es un proceso en el que el otro puede ser un guía, desvelándose a sí mismo o devolviéndonos, como un espejo, nuestra propia imagen.

\section{DIMENSIONES DE LO VISIBLE Y LO INVISIBLE EN EL QI GONG}

Hay una imagen en la enseñanza del Qi Gong que es usada repetidamente: la del bambú. En el pensamiento chino, el bambú evoca las cualidades de un cuerpo armonioso, sólido y flexible. Ante la fuerza del viento, el bambú opone la flexibilidad de su tallo. "El cuerpo debe ser sólido, estable pero flexible y móvil como la danza de un tejido que toma la

3 Se trata del film documental Smirennaja zizn', proyectado en Francia con el título de Une vie paisible, una producción ruso-nipona de 1997, en vídeo, con una duración de 76 min. El documental narra el encuentro con Umeno Mathuyoshi, una mujer anciana que vive en el pueblo de Asuka, en Japón. 
forma del viento. Así debe ser el cuerpo, adaptable a todas las situaciones, circunstancias y momentos, adaptable a todas las personas, a todos los seres", dice el maestro Kar Fung Wu Santaro.

El Qi Gong se orienta a inscribir el cuerpo en el espacio a partir de un trabajo sobre la leyes de la gravitación. El practicante se ejercita a partir de la sensación de la gravedad, anclando sólidamente el pie en el suelo; a través de los gestos y las posturas, "esculpe el cuerpo", endereza el esqueleto de acuerdo a un eje vertical que permite al $Q i$ o soplo vital circular libremente por el organismo. Un eje central, "colonne de souffle", (Zhong Zhu), se desarrolla entonces desde los talones a la fontanela, pasando por el coxis.

En la cultura china, "la lectura del cuerpo" está sólidamente enraizada, el cuerpo es como un texto que hay que descifrar, que puede ser leído e interpretado. Así, para un maestro de Qi Gong, la verticalidad de un cuerpo salta a la vista. La solidez y la flexibilidad responden a parámetros visuales bien concretos: los hombros caídos, los senos frontales prominentes, las caderas abiertas, los tobillos finos, los dedos de los pies separados, las falanges de las manos móviles, la espalda recta, el busto abombado, el cuerpo erguido... son algunos de los elementos de la lectura del cuerpo, signos que permiten descrifrar las cualidades de un ser.

Junto a estos parámetros que configuran la visualidad del Qi Gong, hay una dimensión más difícil de aprehender. "El Qi Gong es una sensación", dicen los maestros. Es un viaje hacia el interior, una forma de meditación muy próxima del Zazen budista. "El Qi Gong no es un aprendizaje, algo que podamos aprender, sino una memoria, un redescubrimiento de la propia memoria" dice Kar Fung. El Qi Gong invoca la memoria prenatal, los gestos realizados en el interior del vientre de la madre, la memoria del silencio, del recogimiento, de la escucha. La imagen del practicante de Qi Gong permaneciendo de pie con los ojos cerrados, concentrado en la respiración y la sensación interna, muestra bien esta dimensión inefable.

Hay en el Qi Gong una vertiente visual evidente que seduce el ojo del cineasta pero que esconde una dimensión más sutil. Las secuencias y los gestos son variados, pero lo importante no es la secuencia, la ejecución del gesto, sino aquello que emana de éste. El gesto es el vehículo del $Q i$, expresión del movimiento interior de vida; se le llama "gesto justo" pues es un gesto que emana del ser profundo, Xing ${ }^{4}$. El "gesto justo"

4 Xing puede traducirse literalmente por "rey" o "jefe" y designa el ser profundo o como dice Kar Fung Wu Santaro "el reino celeste en el interior de nosotros mismos". No se trata de una noción espiritual sino de una realidad energética. Xing es la unión de los tres dan tien o centros energéticos mediante la circulación del Qi. 
es armonioso, fluido, respira, puede verse y sentirse. Es evidente para el ojo entrenado, capaz de percibir lo aparentemente invisible.

\section{EL ÁRBOL, UNA PRESENCIA Y UNA METÁFORA}

El espacio en el que el cuerpo se "enraiza" forma parte del Qi Gong como sistema visual. La presencia del árbol tiene una importancia particular. Tradicionalmente, en China, se practica en el exterior de la casa o en el patio exterior del templo. Tras la destrucción de los templos durante la revolución cultural, el Qi Gong se ha empezado a practicar en los parques y jardines de las ciudades. El intercambio de $Q i$ con un árbol es una práctica corriente. El practicante se coloca cerca o se apoya sobre el tronco del árbol para absorber el $Q i$ benéfico de éste, al mismo tiempo que libera los malos $Q i$, que son absorbidos por el árbol y evacuados en la tierra a través de las raíces.

En París, con la difusión creciente de la disciplina, se han empezado a impartir cursos en gimnasios o domicilios privados; sin embargo, existen varios grupos que practican en los distintos parques de la ciudad como el Luxembourg, los Buttes Chaumont, el Montsouris. Si algunos maestros consideran que ello es un modo de perpetuar la tradición, lo cierto es que los espacios verdes son importantes para la oxigenación del organismo. Los practicantes del René Legall practican el Qi Gong en uno de los caminos más frondosos del square. A ambos lados crecen sicomoros, fresnos, hayas y avellanos. Hace dos años, el grupo se ejercitaba bajo un enorme castaño, uno de los árboles más viejos del parque —un arbre très puissant", dicen los practicantes- algunos se sitúan siempre cerca de ciertos árboles de su preferencia.

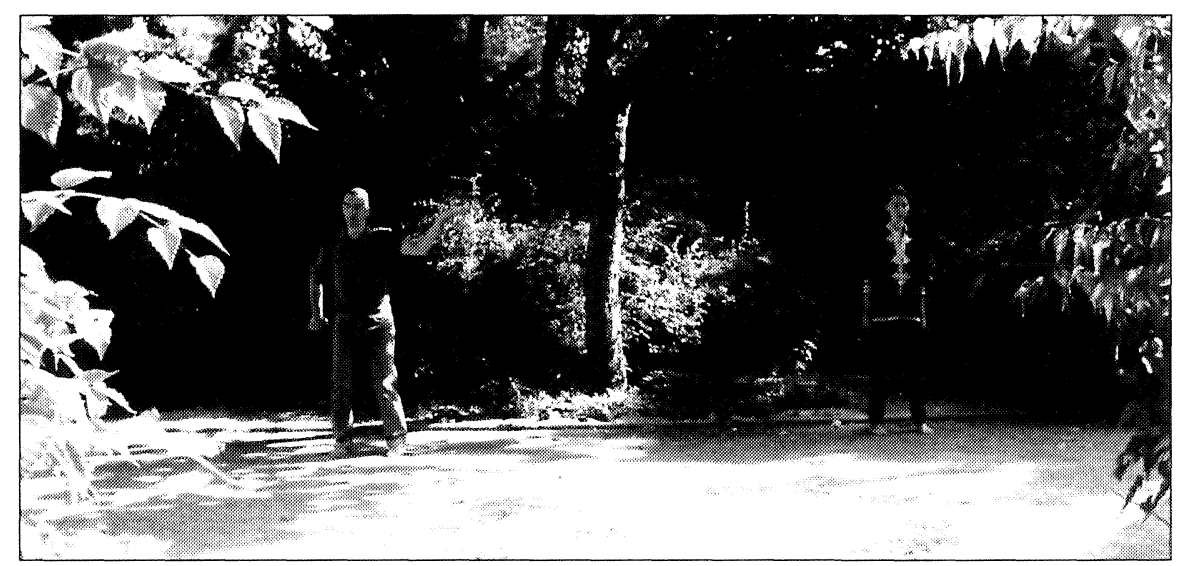


"Los árboles son grandes maestros de Qi Gong", dice Kar Fung. Las raíces que se prolongan bajo tierra y las ramas que ascienden hacia el cielo representan el enraizamiento y el estiramiento del Qi Gong. Como el árbol, el practicante se concentra en sentir el peso de la gravedad, el $Q i$ de la tierra, y la levedad, el $Q i$ del cielo.

"Podrías filmar un árbol. Es la verticalidad del Qi Gong", dice alguien. "El tronco y el follaje de los árboles son como lo que estudiamos en este momento: la estructura ósea y la ligerezan, dice otro practicante. Y es que el árbol representa la solidez del esqueleto y el movimiento ondulatorio del Qi. Forma parte de la visualidad del Qi Gong.

\section{UN LENGUAJE EVOCATIVO}

La antropología visual se abre hoy a dimensiones exploradas desde siempre por los cineastas, que se relacionan con otras categorías del conocimiento como la emoción, la percepción, el tiempo, el espacio: “One of the difficulties of exploring and communicating understandings about them has been finding a language metaphorically and experientally close to them ${ }^{5}$.

"Lo importante no es la secuencia - dice Kar Fung - puedes filmar el movimiento de un brazo y luego la rama de un árbol o filmar un 'mudra' ${ }^{6}$ y la imagen de una flor que se abre. Es su manera de expresar que el lenguaje del Qi Gong es metafórico y que un film debe tener en cuenta esta dimensión. Se trata más de evocar que de describir.

El pensamiento chino es muy visual. Si observamos el ideograma del $Q i$ veremos que está compuesto por un grano de arroz y por vapores que suben de la tierra para transformarse en nubes. Esta representación simbólica indica que el trabajo del Qi Gong consiste en transformar una energía grosera en una energía sutil. El movimiento del $Q i$ en el interior del cuerpo es representado en el pensamiento chino como "el paseo de una mariposa en un jardín zen" o como "una danza de cintas que ondulan al viento", imágenes que evocan aquello que es del dominio del sentir, de lo sensible.

La realización de un film sobre el Qi Gong plantea un problema de lenguaje cinematográfico. ¿Cómo captar o evocar lo invisible, el "Soufflen?

5 Macdougall 1997: 287.

6 Mudras es una palabra de origen sánscrito que significa 'gesto sagrado'. Los mudras son gestos muy elaborados y precisos realizados con las manos. Existe un amplio repertorio de estos gestos en la danza sagrada hindú y en el teatro chino. En el Qi Gong se utilizan para activar la circulación del $Q i$. 
Es interesante a este próposito tener en cuenta cómo la cultura china ha abordado la representación del "Souffle", esa dimensión sutil que forma parte de la naturaleza, el hombre y el universo.

El arte chino, especialmente la pintura, se interesa por lo invisible; el objeto no es lo importante, sino su emanación luminosa. El objeto es el pretexto para contar lo que no se ve. Como dice François Cheng, estudioso de la pintura china, "se trata menos de describir los aspectos exteriores del mundo que de captar los principios internos que estructuran las cosas" ${ }^{7}$. Así, el pintor trata de captar los "principios internos", los $Q i$ o soplos de vida que animan el universo y el hombre. Se interesa más por la representación del cuerpo vibratorio, Shen, que por el cuerpo visible, formado por el esqueleto y los órganos, Ti. Shen designa la dimensión sutil del cuerpo humano, como indica su ideograma, el cual asocia la idea de emanación, con la de resonancia y calor. El cuerpo de Lao Tsé, el maestro taoísta, es usalmente representado a través de una ausencia de color, que evoca transparencia o emanación luminosa. En el film, esa dimensión invisible es evocada a través de diferentes imágenes: la nube que pasa lentamente - y que en la pintura china representa el vacío, el lugar en el que todas las transformaciones son posibles-, el movimiento de las hojas, un soplo de aire, los rayos de sol a través de las ramas...

"El Qi Gong c'est du silence et de la lumière", me dice un practicante para quien el silencio y la luz evocan más cosas que las palabras.

Como dice McDougall, "Filmmakers have shown a growing interest in precisely those things that cannot be seen $-\mathrm{y}$ añade pensando en el film antropológico-: there is thus in ethnographic filmmaking not only a journey of discovery from the abstract to personal but from representation to evocation" 8 .

\section{PRIMERAS REACCIONES A LA IDEA DE UNA FILMACIÓN}

La primera vez que hablé a Kar Fung de mi deseo de realizar una película sobre el trabajo del grupo, su respuesta fue muy clara: “No es posible. Hay mucha gente enferma en el grupo que no desearía que les filmaran. Hay momentos muy duros, muy dolorosos, muy íntimos. Sería violento para ellos". Estas palabras ponían de relieve la privacidad del ejercicio, el hecho de que el Qi Gong, a pesar de practicarse en un lugar

\footnotetext{
7 CHENG 1991.

8 Macdougall 1997: 249.
} 
público a la vista de todos, tiene una dimensión privada, es algo particular y personal de cada uno.

En los últimos años, varios equipos de televisión, franceses y extranjeros, han intentado realizar reportajes o films documentales sobre el trabajo del grupo y, en particular, en torno a la figura de Kar Fung. Este ha rechazado sistemáticamente toda propuesta por respeto al trabajo de su grupo y por su afán de no hacer proselitismo alguno. En una ocasión, contó que, hacía unos años, un pequeño equipo había tratado de rodar el grupo a escondidas, con un teleobjetivo. "Me he negado a convertirme en una imagen", dice, manifestando así su deseo de no ser mediatizado.

A pesar de esta primera reacción, de la imposibilidad de grabar al grupo durante las horas de práctica, me parecía importante hacer un film que mostrara lo que es el trabajo colectivo del Qi Gong. De hecho, al inicio de mi investigación, algunos practicantes me habían sugerido la idea de hacer una película; la experiencia del Qi Gong es muy personal y a menudo mis interlocutores tenían la impresión de no poder comunicar con las palabras. Les parecía que la imagen podía ser más evocadora y sugerir lo que la palabra no podía nombrar. Inspirada por estas voces pensé en lo que era factible e imaginé la posibilidad de invitar a un grupo de gente voluntaria a hacer una sesión de Qi Gong, fuera de las horas de curso, que sería filmada. Cuando comenté mi propósito a algunos practicantes del grupo, las reacciones fueron diversas. Algunos, efectivamente, se mostraron indiferentes o escépticos: "Es muy difícil entrar en el mundo interior", "la única manera de comprender el Qi Gong es practicar". Algunos reaccionaban con reserva, me decían que no se consideraban suficientemente avanzados en la práctica como para ser filmados. Sin embargo, para un buen número, el film no planteaba problema alguno. Se mostraban cooperativos e interesados, y algunos incluso entusiastas ante la idea de dar a conocer el Qi Gong.

En uno de los cursos que suceden al ejercicio práctico del Qi Gong se distribuyeron unas hojas al grupo, invitando a todo aquél que quisiera a una sesión de Qi Gong, fuera de las horas de curso, en el lugar habitual. Hay que señalar que Kar Fung estuvo de acuerdo con la idea y que colaboró sugiriendo imágenes y dando consejos. Enfatizó que lo importante era el hecho de ofrecer a la gente la posibilidad de hacer una sesión complementaria. "Tiene que ser un verdadero Qi Gong, que todo el mundo pueda aprovechar", manifestó, pensando en la gente enferma que podría así aprovechar la energía del grupo. 


\section{UN DISCURSO SOBRE LA "EMANACIÓN"}

La filmación ha generado un discurso que gira en torno a la noción de emanación; se habla de la emanación del lugar de la práctica, la emanación del grupo y la emanación del gesto o del cuerpo.

Los practicantes consideran que el camino donde se practica habitualmente el Qi Gong está "cargado" de energía. "Veinte años de práctica han 'cargado' el lugar. Han modificado la energía del sitio... Hay una emanación del lugar, en realidad se trata de un campo magnéticon. Según este discurso, el lugar tiene unas particularidades energéticas que justifican la orientación de los practicantes. "Este lugar tiene una orientación. Los árboles de este lado no emanan lo mismo que los de ese lado. Tienen mucha fuerza porqué durante muchos años la gente que ha venido a practicar el Qi Gong los ha estado mirado". Así, a pesar de algunos inconvenientes técnicos para tomar planos generales, se insiste en no modificar nada.

Se pone de relieve la importancia de practicar en grupo. Esa energía va a reflejarse en la película. "El grupo emana una formidable energía. Es un núcleo de energía. Cada persona aporta una fuerza a su medida. Es un trabajo común". "La emanación del grupo es importante, impregnará la película".

Se habla también de la emanación del gesto. Un gesto auténtico de Qi Gong es aquel que "emana". Esta emanación puede "sentirse".

\section{DEFINIENDO ALGUNOS CRITERIOS DE GRABACIÓN}

Los criterios de grabación se van definiendo con el concurso de los practicantes.

Todo el mundo está de acuerdo en que no habrá que actuar para la cámara, que habrá que intentar hacer abstracción. Sólo así el film podrá tener una validez.

Como es imposible planificar la sesión que debe transcurrir de la forma más espontánea posible, se decide grabar con dos cámaras de vídeo. Una grabará en continuidad, para no tener problemas en el proceso de edición y sobre todo para no perder el momento en que los practicantes iniciarán los movimientos gestuales. La otra tendrá más movilidad y buscará la variedad de planos.

Los practicantes subrayan que lo importante es hacer Qi Gong. Será necesario "enraizarse" para poder realizar un gesto auténtico, un gesto que sea vehículo del "Souffle. "Será necesario que estemos enraizados, si no 
el gesto será falso... Tendrás que dejarnos todo el tiempo que nos haga faltaw.

Se acuerda que los practicantes permanecerán en "verticalidad", los pies paralelos, concentrados en las sensaciones interiores, tanto tiempo como les sea necesario. En la práctica del Qi Gong se considera que son precisos unos cuarenta y cinco minutos de "verticalidad" para que el cuerpo haga el "lâcher-prise", se abandone. Este tiempo es necesario para entrar en contacto con "la raíz del souffle", que se halla en los talones y para que el cuerpo "se alinee" permitiendo la libre circulación del $Q i$ por los distintos canales energéticos que recorren el cuerpo. Sólo tras esa fase se encadenan los gestos y movimientos. Como la sesión filmada tendrá lugar tras una mañana de ejercicio práctico, muchos consideran que no será necesario tanto tiempo de enraizamiento.

Una practicante que da habitualmente cursos de Qi Gong se ofrece a dirigir la sesión y "sentir" el momento en que el grupo esté preparado para la ejecución de los gestos.

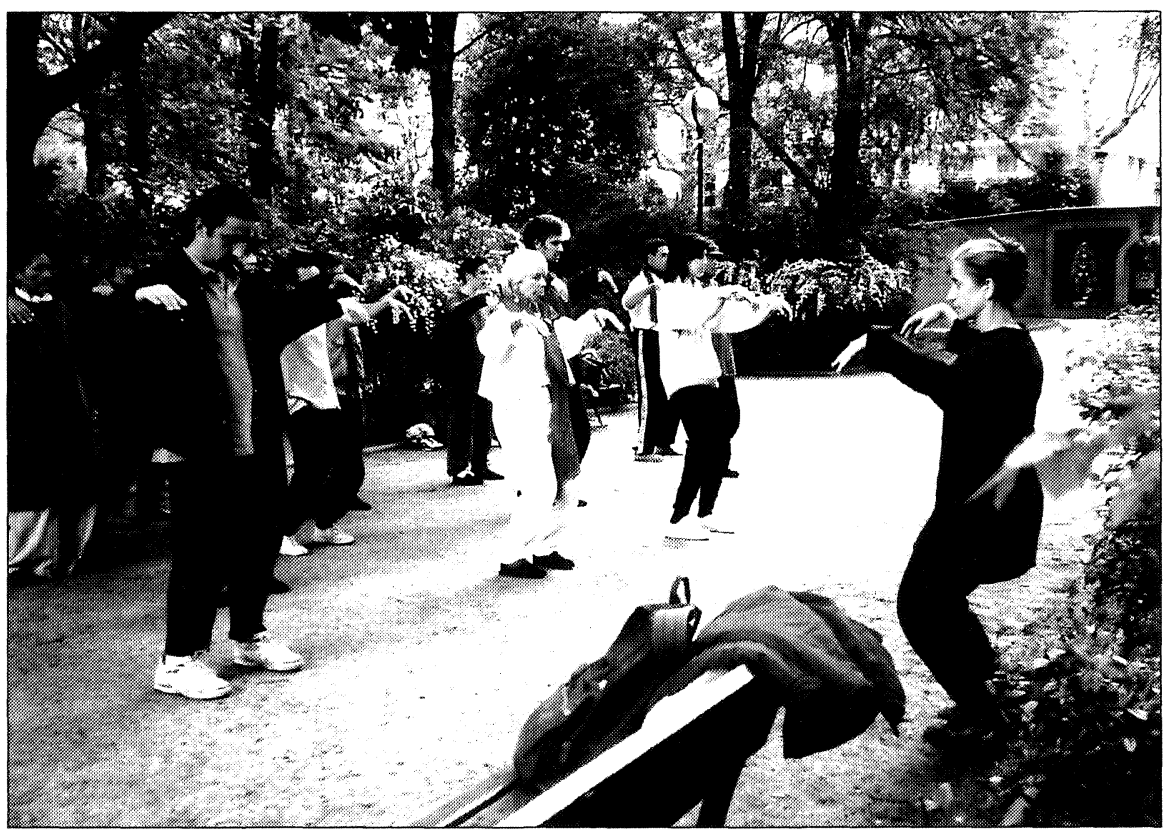

Los practicantes ponen énfasis en la autenticidad de la sesión. La cámara deberá adaptarse al ritmo de los practicantes. "No se puede hacer trampan. 


\section{GRABANDO UNA SESIÓN DE QI GONG}

El día fijado para el rodaje, una veintena de personas acuden al camino en el que habitualmente se realiza el Qi Gong. Desde las ocho y media de la mañana han practicado Qi Gong y Tai-Ji; hay gente cansada o hambrienta y hay que ir rápido. Se instalan las dos cámaras de vídeo. Una de ellas cubre un plano general de referencia y graba en continuidad. La otra, más móvil, cubre otros ángulos y grabará planos más cerrados.

Tras unas breves indicaciones, las cámaras empiezan a grabar. De un lado y otro del camino de tierra, los practicantes van llegando, depositan sus cosas sobre los bancos del parque y buscan un lugar para emplazarse. Cada uno se coloca en postura de Qi Gong, se concentra. Pocos minutos después, empieza a llover. Los dos operadores deben proteger los objetivos, unos segundos de filmación se pierden mientras se colocan los plásticos para tapar las cámaras. Lo extraordinario es que ninguno de los practicantes se mueve, nadie parece prestar atención a la lluvia... esa quietud es algo fuera de lo normal, como si hubiera un acuerdo tácito, una puesta en escena espontánea.

La persona que guía la sesión improvisa los movimientos olvidando el programa previsto para el rodaje. Decide realizar los mismos movimientos que el grupo ha practicado por la mañana... "Il faut laisser faire, laisser agir" 9 dicen los practicantes. Lo importante es sentir, dejar que el gesto surja, espontáneo, en el aquí y ahora.

\section{REACCIONES}

"Ha habido algo", dicen algunos. Ese "quelque chose" es ese algo indefinido y sin embargo esencial al Qi Gong, es el signo de que se ha hecho un buen Qi Gong. Las reacciones tras la grabación son variadas. Algunos dicen que no han podido concentrarse, "on a fait du cinéma". La mayoría sin embargo lo ha logrado. "Para mí ha sido como cualquier otra

9 Es la formulación del célebre principio de Lao Tsé denominado "wu wei", traducido a veces como "no actuar". En realidad se trata de actuar en armonía con el curso natural de las cosas, dejándose llevar y no oponiendo resistencia. El significado del ideograma que representa esta noción es sin embargo más complejo. Wu es el instante del cuarentavo día correspondiente a la manifestación del $Q i$ del diafragma. Wei indica la ondulación y el eje oblícuo. Wu Wei es, por lo tanto, un estado en el que uno está conectado con la memoria embrionaria que en la cosmología china corresponde a la memoria cósmica universal. 
sesión de Qi Gong", "yo he sentido algo que se ha desbloqueado en mi cuerpo", "ha sido magnífico, ha llovido, ha salido el sol y se ha levantado el vienton. El rodaje es una ocasión para reunirse y compartir un tiempo. "Habría que hacer cosas así más a menudo", concluye alguien.

Unos días mas tarde, las fotos que se hicieron durante el rodaje circulan por el grupo. Es una ocasión para observarse, para hablar de los unos y los otros. Se subraya la evolución de ciertas personas a quienes la práctica del Qi Gong ha ayudado a superar una enfermedad o un desequilibrio psíquico. Se pasa revista a las posturas de cada uno. La lectura del cuerpo es muy precisa: “Mira, la nuca está 'cassée' ${ }^{10}$, ella tiene los pies bien posados en el suelo pero sus hombros no están relajados", "Sus pies no están anclados", "el vientre está demasiado salido, está fuera del eje", "yo tampoco estoy vertical". Hay personas que han preferido no venir al rodaje porque no se consideran suficientemente avanzadas en la práctica o en la justeza de sus posturas: "No he venido porque mi postura todavía no es juste, ${ }^{11}$, dice alguien.

Lo importante es poderse ver, advertir los propios errores para corregirlos. El trabajo de corrección de las posturas es lento y adquirir el "eje vertical" puede durar años, como testimonian muchos practicantes: "Todavía queda mucho por hacer!n.

\section{CONCLUSIÓN}

Durante la realización de la película, los practicantes de Qi Gong se han manifiestado sobre algunos criterios necesarios para filmar "un auténtico Qi Gong".

Si el Qi Gong es un arte y un saber médico basado en conocimientos muy elaborados sobre el cuerpo humano, es también una experiencia hecha de espacio y tiempo. A través de la interacción creada con los practicantes a propósito del film, la dimensión inefable y visual del Qi Gong se manifiesta claramente. Este aparece como un sistema visual complejo que afecta los modos de ver el cuerpo y de percibir el gesto y el movimiento en sus aspectos más sutiles. Su práctica desarrolla una forma de observar y "leer" el cuerpo en la que las características del cuerpo visible son expresión de las cualidades del alma. El ojo del cineasta debe entrenarse para captar el "Souffle", para discernir los falsos gestos de los verdaderos que unen el mundo visible al invisible.

10 "Cassée" es rota. En el Qi Gong las "cassures" indican los bloqueos energéticos.

11 "Juste" quiere decir aquí 'ajustada'. La postura o el gesto justo en el Qi Gong indica la armonía entre el cuerpo físico y el cuerpo vibratorio. 
Por otro lado, el lugar en el que se practica el Qi Gong en el square René Legall, un camino rodeado de árboles que induce a la introspección, forma parte de la visualidad de la práctica. El Qi Gong es vivido como una experiencia interna hecha de imágenes, sonidos, silencios. El Qi Gong pone en juego el cuerpo, la postura y el movimiento, el ritmo y la respiración... es un lenguaje visual que apela a lo sensible.

Como dice Elizabeth Chaplin, images are able to capture and convey aspects of society which words cannot and therefore are clearly capable of altering or adding to our social scientific understanding of $i t^{12}$.

\section{BIBLIOGRAFÍA}

BANKs, Marcus \& Howard MORPHY (eds.), 1997: Rethinking Visual Antbropology, New Haven: Yale University Press.

Buxó, María Jesús y J. DE Miguel, 1998: De la investigación audiovisual; fotografía, cine, vídeo, televisión, Barcelona: Proyecto A Ediciones.

CHAPLIN, Elizabeth, 1994: Sociology and Visual representation, London: Rouledge.

CHENG, François, 1991: Vide et plein, le langage pictural cbinois, Paris: Seuil.

Devereux, Leslie \& Roger Hillman (eds.), 1995: Fields of vision, Berkeley: University of California Press.

Dumoulin, Heinrich, 1992: Zen bouddhism in the 20th century, New York: Weatherhill. GRANET, Marcel, 1968: La pensée chinoise, Paris: Albin Michel.

Hockings, P. \& Y. OMORI, 1988: "Cinematographic theory and New dimensions in ethnographic film", Senri Ethnological Studies, 24.

MaCDOUGall, David, 1997: "The visual in anthropology", en M. Bancks \& H. Morphy (eds.), op. cit.

Pbilosophes taoïstes, Lao-Tseu, Tchouang-Tseu et Lie-Tseu, 1996, trad. y pres. Liou KiaHway et Benedikt Grynpas, Paris: Gallimard.

Rouch, Jean, 1979: "La caméra et les hommes", en Claudine de France (ed.), Pour une Anthropologie Visuelle, Paris: Mouton-Ehess.

SEBASTE, Beppe, 1997: "Kar Fung Wu Santaro insegnante di Qi Gong e di Tai Chi, custode della memoria e formatrice di uomini", en Porte senza porta. Incontri con maestri contemporanei, Milano: Giangiacomo Feltrinelli.

Sheng Zhu, Mian, Michel Angles \& Siavoch DaraKchan, 1994: Souffle et énergie. Le Qi Gong, Rodez: Rouergue.

SILBURN, Lilian (dir.), 1985: Tch' an-Zen, racines et floraisons, Paris: Deux Océans.

SuzUKI, D. T., 1972: Essais sur le bouddhisme zen, Paris: Albin Michel.

12 ChAPLIN 1994: 232. 
Se analizan algunas cuestiones suscitadas a raíz de una filmación sobre la práctica de una disciplina corporal china de tipo energético, el Qi Gong, en un pequeño jardín de París. La visualidad del Qi Gong comprende una lectura muy precisa del cuerpo y una dimensión sutil que puede escapar al ojo no entrenado. La filmación genera un discurso que permite valorar determinados aspectos relacionados con la ética, la privacidad de esta práctica y la emanación energética.

I address some questions raised on the filming of a Chinese body exercise, the Qi Gong, in a small garden of Paris. The exercise implies a theory on energy and its visual representation includes a very precise reading of the body and other signs, the significance of which can be missed by the untrained eye. The filming generates a discourse that bears on the larger issues of ethics, privacy and the idea of the emanation of energy. 